\title{
A Case Study of Pragmatic Failures
}

\author{
Committed by Undergraduates
}

\author{
Yan Qiao \\ Foreign Language Department \\ Luoyang Institute of Science and Technology \\ Luoyang, China \\ e-mail: madison1980@163.com
}

\begin{abstract}
This study conducted at one university in Guangzhou, mainly examined the English majors' pragmatic failure in both verbal and nonverbal communication and explores the possible causes from students' perspectives. Combination of quantitative method and qualitative method were employed in the research including testing, questionnaire, interviews and observation. The results indicate that the average pragmatic competence of the subjects is still in a poor level. They committed pragmatic failure not only in verbal communication but also in nonverbal one. The study explored the causes of the failures from learners' perspective and offered implications for further research.
\end{abstract}

Keywords-pragmatic failuret; verbal communication; nonverbal communication; causes

\section{INTRODUCTION}

To satisfy the need of social development in China, the focus of English language teaching has shifted to cultivate learner's communicative competence. Pragmatic competence is an important component of communicative competence and it is defined as "the ability to use language effectively in order to achieve a specific purpose and understand language in context" [1]. Pragmatic competence is concerned with the ability to apply the knowledge of the grammar and vocabulary of the language. Traditional English teaching and learning has laid much emphasis on grammatically correct sentences and largely ignored the cultivation of students' pragmatic competence---the ability to use language effectively in order to achieve a specific purpose and understand language in context, which lead to Chinese English learners' pragmatic failure in intercultural communication.

The study of pragmatic failure in China can be traced back to the mid of 1980's and subsequently many scholars have turned their attention to this field. However, there are still some identifiable gaps. Firstly, according to Li Yuan-sheng[2], pragmatic failure also occurs at the level of nonverbal communication. However, there are few studies that have ever investigated learners' pragmatic failure in nonverbal communication. Secondly, few researchers have taken the investigation to make comparison between those who have learned the course of intercultural communication and those who have not since cultural knowledge plays a vital role in improving learners' pragmatic competence. Thirdly, the previous studies usually require the subjects to take a written test to examine their pragmatic failure, which can not totally reflect the learners' pragmatic competence in real context. Therefore, this empirical study, integrating quantitative and qualitative research methods, was designed to fill the gaps.

\section{PURPOSE OF THE RESEARCH}

The main purpose of this study is: firstly to examine the English majors' pragmatic failure in both verbal and nonverbal communication and their pragmatic competence by means of four different techniques used for data collection, namely, written test, questionnaires, videotaped observation and semistructured interviews; secondly, to analyze the factors that causes the pragmatic failure from learner's perspectives and thirdly try to propose some ways to improve their pragmatic competence accordingly.

The study is intended to answer the following research questions:

1) What is students' pragmatic competence examined through test and observation?

2) Will students commit pragmatic failure in non-verbal communication? If they will, what might be those failures?

3) What will be the causes of pragmatic failure from students' perspectives?

4) Will the pragmatic failure be lessened after taking the course of intercultural communication?

\section{METHODOLOGY}

This study, conducted at one university in Guangzhou, mainly examined the English majors' pragmatic failure in both verbal and nonverbal communication and explored the possible causes from students' perspectives. The theory used was mainly based on Jenny Thomas[1] pragmatic failure theory and speech act theory [3].

\section{A. Subjects}

The subjects of this study were English majors from one university. One of the purposes of this study is to investigate if the pragmatic failure is lessened or eliminated after English learners have taken the course of intercultural communication. This course was offered in the second semester of Grade three 
for English majors. So, two classes of English majors were selected from Grade Two and Grade Four respectively. They have studied English systematically for seven and nine years. It means they have mastered necessary grammatical knowledge to accomplish the task. The students in Grade Four had two years longer English learning experience and finished most courses of specific English training in college and they just had the course of intercultural communication the term before. The seniors should have grasped basic cultural knowledge and a high proficiency of English skills. So the seniors were assumed to have better pragmatic competence. Four of these students were picked up to be informants in observation and interview according to their scores in written test.

\section{B. Methods}

The study integrated quantitative and qualitative research and applied multiple methods to collect data which was listed as follows:

Firstly, a written test was designed to find out students' pragmatic failure and examine their pragmatic competence both in verbal and nonverbal levels. The test paper contain two parts: the first part of 40 multiple choice questions mainly focused on verbal communication; the second part consisted of 10 True or False statements which concerns nonverbal communication. The first part of the testing paper involved the following items of speech acts in Table 1:

Table.1. Speech acts in part I

\begin{tabular}{|c|c|c|}
\hline Speech acts & No. of questions & Total number \\
\hline Apology & 1,2 & 2 \\
\hline Response to complain & 3,23 & 2 \\
\hline request & $4,5,7,19,24,25,26,29,30,34,35,38$ & 12 \\
\hline compliment & $8,9,28$ & 3 \\
\hline refusal & 10,16 & 2 \\
\hline requiring & $11,18,32$ & 43 \\
\hline greeting & $12,13,14,17,21,22,36,37$ & 8 \\
\hline farewell & $20,27,33,40$ & 4 \\
\hline others & $6,15,31$ & 3 \\
\hline
\end{tabular}

Table 2. Items in part II

\begin{tabular}{|c|c|c|c|}
\hline Categories & items & No. of question & Total number \\
\hline \multirow{3}{*}{ kinesics } & Facial expression & 0 & 0 \\
\cline { 2 - 4 } & Eye contact & 3,4 & 2 \\
\cline { 2 - 4 } & gesture & $5,9,10$ & 3 \\
\cline { 2 - 4 } & touch & 2,6 & 2 \\
\hline proxemics & Use of space & 7,8 & 2 \\
\hline paralanguage & Sounds, not words & 0 & 0 \\
\hline chronemics & Use of time & 1 & 1 \\
\hline
\end{tabular}

The second part of testing was $\mathrm{T}$ or $\mathrm{F}$ statements concerning nonverbal communication. It included following items in Table 2:

The second method was questionnaire followed the testing. The questionnaire included 15 questions which aimed to understand students' background information and explore their attitudes toward cultural learning with regard to the textbooks and classroom teaching.
Semi-structured interview can yield a variety of kinds of information that can't be got only through questionnaire. By doing this one can gather factual information about people's circumstances, collect statements of their preferences and opinions, and explore in some depth their experiences, motivations and reasoning. Therefore, the interviewed was conducted after the questionnaire to collect more detailed information concerning learners' learning experiences, attitudes and causes of pragmatic failure from their perspectives.

In addition, the method of observation was conducted to reexamine their competence in an authentic context by speaking with a native speaker. observation was supplemented to enrich data gathered by other techniques because the records made through observation was more detailed and more direct than data from any other source. The participants were asked to hold a conversation with native speakers with certain setting. The researcher made records of this whole process by a video camera and made analysis afterwards to see what pragmatic failure they committed. A comparison was made between observation and testing to see if the data collected from these two ways were consistent with each other. In this way, we can have a better understanding of students' pragmatic competence in real communication.

\section{RESULTS AND DISCUSSION}

The data collected through testing and questionnaire were described and analyzed with the help of statistical software Microsoft office Excel2003 and Origin7.0.

The qualitative data collected from observation and interview were analyzed in three steps: 1) transcribing video and tape recordings. For observation and interview, the participants' dialogue and responses were recorded on MP3 and a video tape. The sound information was taken down and transcribed into protocols. 2) segmenting the data in relation to a specific research question; 3) displaying the segmented data in a table.

The findings were presented in the following parts to answer the research questions.

\section{A. Overview of students' pragmatic competence}

Table. 3. Overview of students' pragmatic failure

\begin{tabular}{|c|c|c|c|c|c|c|}
\hline & \multicolumn{2}{|c|}{$\begin{array}{c}\text { Average rate of } \\
\text { failure }\end{array}$} & \multicolumn{2}{c|}{$\begin{array}{c}\text { Maximum of incorrect } \\
\text { answer }\end{array}$} & \multicolumn{2}{c|}{$\begin{array}{c}\text { Minimum of incorrect } \\
\text { answer }\end{array}$} \\
\hline & Part I & Part II & Part I & Part II & Part I & Part II \\
\hline Two & $45.7 \%$ & $38 \%$ & 30 & 10 & 11 & 1 \\
\hline Four & $44.5 \%$ & $36 \%$ & 29 & 6 & 10 & 1 \\
\hline
\end{tabular}

Table 3 shows the students' general tendency of pragmatic failure in verbal and nonverbal communication through a written test.

The figures show that the seniors who were more proficient in linguistic competence performed only slightly better than the sophomores in this university. The pragmatic failure rate in 
pilot study shown in Table 1 is very close to the result here, which proves the relativity and consistency of the study. The data gathered from observation also verified this and came to the conclusion that the pragmatic competence of the subjects is not necessarily development together with their linguistic competence. The subjects in Grade Four are not necessarily more significantly competent in pragmatics than those in Grade Two. This is also found in other researches done by XuPing [4]and PengYing [5]. In their investigations, they all found that there is no significant difference in pragmatic competence among the groups who differ in their English learning experiences.

\section{B. Results from testing}

Table. 4. Frequency distribution of part I

\begin{tabular}{|c|c|c|c|c|c|c|c|c|c|c|c|c|c|c|c|c|c|}
\hline $\mathrm{Fre}_{\mathrm{N}}^{\mathrm{NIA}}$ & 10 & $11+$ & $13+$ & 14 & 15 & $16 \%$ & 17 & $18+$ & 19. & 20 & $21+$ & 22 & $23+$ & 24 & 29 & 30 & Totale \\
\hline $\begin{array}{c}\text { Grade } \\
\text { Two }\end{array}$ & 0 & 10 & 2 & 4 & 4 & 90 & 4 & 6 & $11+$ & 80 & 3 & 3 & 4 & 10 & 0 & 1 & 61 \\
\hline $\begin{array}{l}\text { Grade } \\
\text { Four }\end{array}$ & 1 & 1 & 7 & 2 & 0 & 7 & 12 & 80 & $11 \%$ & 5 & 2 & 5 & 3 & 0 & 10 & 0 & 65 \\
\hline
\end{tabular}

(NIA: Number of Incorrect Answers; Fre: frequency)

Table 4 shows the frequency distribution of incorrect answers in part I of the test. Generally, only when the rate of incorrect answer is under $40 \%$, can we say the student passes the examination. Following this principle, the number of incorrect answers should not exceed 16 in part I. In this test, there were altogether 88 students, which accounted for $70 \%$ of the students failed in this test. The average rate of pragmatic failure is $45 \%$, as shown in Table $4-1$. These figures reveal that the pragmatic competence of the subjects is still at a poor level. This finding is consistent with that in other investigations done by Li Yue-e [6], XuPing [4], Li Chen-fang [7], Gu Tongqing [8] and other scholars and researchers. These findings demonstrate that the general pragmatic competence of Chinese English learners, from high school student to postgraduate, whether English majors or not, is lower than expected. Those who have a good command of linguistic knowledge do not necessarily grasp the appropriate expression for certain situation with an English cultural context. The previous studies usually provide a figure of general pragmatic failure without concerning to specific speech acts (such as XuPing[4]) or confined to only one speech act (such as Li Yue-e[6]).

If we took a close examination to the results from the testing ,we found that: 1) Negative language transfer plays a vital role in causing pragmatic failure. The students tended to transfer the Chinese form of speech directly into English regardless of the different principles rooted in value systems and beliefs. 2) We can also see some progress in some frequently-studied and related speech acts which are more close to our daily life such as compliment and greeting. But, for some complicated speech acts such as request and refusal or some formulaic expression in specific situation, the pragmatic failure is serious and the teaching and learning of these speech act realization patterns should be embraced into classroom English teaching. 3) Some native speakers who have read the test said that for some questions there may be more than one correct answers and the difference is just so slight. The choices sometimes are vague without indicating the situation or specific social distance between the speakers. Language is flexible but we are often taught to choose one correct answer. This is also the problem of teaching system and design which need to be improved.

\section{Results from observation}

In order to examine language learner's pragmatic competence in real-life situations, this study made an attempt to simulate a context in which the subjects were asked to accomplish a task that is to invite the native English teacher to an English corner and hold a small talk with her. There are few investigations that have ever applied this method and this study is making a trial and providing some insight for further study. Four students participated in this activity. They were student A who got the highest in Grade Two, student B who got the lowest in Grade Two, student $\mathrm{C}$ who got the highest in Grade Four and student D who got the lowest in Grade Four.

It was found that the subjects in Grade Four did not show too much advancement in pragmatic competence than those in Grade Two. But the subjects in Grade Four did better in fluency and organizing their ideas in answering the NS' questions and made less grammatical mistakes than subjects in Grade Two. This revealed that Chinese English learners' pragmatic competence did not developed along with their linguistic competence due to the over-emphasis of examination system and language teaching on single word explanation and grammatical rules.

From observation, we found that the students can follow the native speakers to accomplishing a conversation even though they made grammatical mistakes. In terms of speech acts, we found that they could fulfill some basic speech acts such as greeting and farewell which did not command much technique. For the speech acts such as request and compliment which differ a lot between Chinese and English culture, the students could not get rid of negative language transfer and commit pragmatic failure unconsciously even though they have already been aware of the difference such as compliment.

\section{Comparison between the results from testing and observation}

A comparison was made between observation and testing to see if the data collected from these two ways were consistent with each other. It is assumed that they may give correct answers in written form but fail to express themselves properly when talking with native speakers for various reasons. Through comparison we can have a better understanding of students' pragmatic competence in real communication.

By comparing the data collected through observation and testing, we found that Chinese English learners' pragmatic competence in live communication was not totally correspond with their performance in written exam. For greeting request and farewell, they could accomplish it in live communication by employing the simplest patterns of the speech acts. However, when the situation becomes a little complicated, they may not handle it as well as what they did in the test. For compliment, even though they all knew the right way to 
respond to a compliment in the test, when it came to the real communication their first reaction still remained in a Chinese way to respond. So, Chinese English learners' pragmatic competence should be improved by immerging more in a live English environment.

\section{E. Failure in nonverbal communication}

Table. 5. Frequency distribution in Part II

\begin{tabular}{|c|c|c|c|c|c|c|c|c|c|c|}
\hline Fre NIA & 1 & 2 & 3 & 4 & 5 & 6 & 7 & 10 & Average & Total \\
\hline Grade Two & 4 & 4 & 22 & 12 & 13 & 4 & 1 & 1 & 3.8 & 61 \\
\hline Grade Four & 9 & 9 & 13 & 14 & 8 & 10 & 2 & 0 & 3.6 & 65 \\
\hline Total & 13 & 13 & 35 & 26 & 21 & 14 & 3 & 1 & 3.7 & 126 \\
\hline
\end{tabular}

Table. 5 shows frequency distribution of the number of incorrect answers for Part II nonverbal communication. These figures demonstrate that these English learners do commit pragmatic failure in nonverbal communication and the average rate of pragmabehavioral failure in this test is $37 \%$. The average rates of pragmabehavioral failure for Grade Two and Grade Four are quiet similar, which are $38 \%$ and $36 \%$ respectively. With another two years of language learning, the subjects of Grade Four did not show much advancement than those of Grade Two in nonverbal communication. This also proved that those subjects' pragmatic competence did not develop even though their linguistic competence improved with two more years of study.

\section{THE CAUSES OF FAILURES}

The questionnaire and its statistics provided students' general background and attitudes towards English learning and teaching. The interviews offered more detailed information concerned with the cause of pragmatic failure from students' perspective. By analyzing the statistics of questionnaire and the script of interview, we summarized the causes of learners' pragmatic failure as follows:

\section{A. Negative language transfer}

The students' choices in the test and performances in observation again demonstrated that negative transfer directly lead to pragmatic failure. Negative transfer is one of language transfer and defined as the effect of one language on the learning of another. Negative transfer is the use of a nativelanguage pattern or rule which leads to an error or inappropriate form in the target language. The research on interlanguage pragmatics also shows that the first language will inevitably cause negative language transfer to the second language in foreign language learning. Pragmatic failure caused by negative transfer also reflected in this investigation such as students' realization pattern of request and their responding to compliment. Moreover, in the interviews with Student A and Student B, when asking why they chose "It doesn't matter" as the response to an English apology in Question 1, both of them explained that it is because "It doesn't matter" lexically equals to Chinese word "mei guan xi" which is the response to a Chinese apology. "Still the Chinese way of thinking", as Student B said.

\section{B. Teaching and learning materials}

The present teaching and learning materials still can not meet students' expectation for cultural knowledge and cultural teaching. According to the statistics of questionnaire, $90 \%$ of the subjects are interested in cultural knowledge while about $49 \%$ of them hold that there is comparatively little knowledge about cultural differences in their learning materials. About $60 \%$ of the subjects think that nonverbal communication is important whereas only $7 \%$ of them think that there are enough knowledge of that in their materials and there are few textbooks that have ever introduced the pragmatic knowledge with cultural background systematically.

However, the statistics also showed that the seniors who have learned the course of cross-culture communication became more aware of cultural difference. This suggests that the cultural background knowledge serves as the basis but it is not enough. The different pragmatic rules of realization pattern of specific speech acts between Chinese and English should be embraced in the course.

\section{Classroom teaching}

The interviews with students show that there are some problems in English classroom teaching. On one hand, teachers lay more emphasis on grammatical and text explanation, and ignored pragmatic knowledge. On the other hand, teachers still adopt a teacher-centered mode in classroom teaching and it is monotonous. Students have few chances to interact with the teacher or with themselves.

The above three causes are already mentioned by scholars theoretically and confirmed by the questionnaire and interviews conducted in my study. The next two causes are found exclusively in interviews and questionnaire of this study.

\section{Individual learning techniques}

There is tremendous variety in the techniques employed by different learners. They will be dealt with in two groups: those involved in studying the second language, and those involved in obtaining second language input (Ellis, 1985). For the first group of learners, they learn grammar, vocabulary or pronunciation by memorizing and practicing by themselves. The second group of learning techniques concerns the ways in which the learner gets into contact with the second language. Learners often seek out situations in which they can communicate with native-speakers, or they make use of the radio or cinema to get maximum exposure to the second language [9]. Student $C$ belongs to this group of learners and her learning techniques contributed a lot to her good mark in the test and natural and fluent English in communication with the native speaker in observation. She said the questions were easy to answer because she has met them before.

Compared with SC, the other informants did not pay much attention to cultural difference in their study. When they read books or heard from their English teachers they did not make any notes so that the points just faded away gradually from 
their minds. Besides, they seldom get exposure to English environment on purpose.

\section{E. Lack of English environment}

Because of the large population of English learners in China, there are few opportunities for Chinese English learners to speak to the native speakers and get involved in idiomatic English conversations. Although schools have expanded the amount of foreign teachers, it still can not meet the great demands. Lacking of the English environment, students have few chances to practice oral English with native speakers. It is surprising to know that Student D has never talked with a native speaker during four years of English academic study. It is even hard for some students to get involved in real English conversations such as in TV or movies.

Furthermore, the foreign teachers' teaching competence and technique differ a lot. Some foreign teachers can design their lessons favorable to the students and students can really learn something from the class while some can not and bring about students complaints.

\section{CONCLUSION}

This study, conducted at one university in Guangzhou, mainly examined the English majors' pragmatic failure in both verbal and nonverbal communication and explored the possible causes from students' perspectives.

This study offered some potential contributions to the study of pragmatic failure and the EFL teaching in China. This study is to extend the research of pragmatic failure from verbal to nonverbal communication and made an attempt to evaluate students' pragmatic competence in an authentic context. The comparison between data from two Graders offered an insight that culture teaching should integrate pragmatic rules in speech act realization pattern to improve students' pragmatic competence. The semi-structured interview explored the causes of pragmatic failure from learners' perspectives.
However, there might be some limitations in the research, like the deficient items in non-verbal communication due to the lack of previous studies in this aspect, affective factors considered in students' performance in observation and the investigation only conducted within one university.

Therefore, we suggested that, in further study more attention should be laid on language learners' pragmatic failure in nonverbal communication and the data of observation should be collected in a more natural state, such as without subjects' awareness. A wider range of study should be conducted in different places of our nation and the result might be more solid.

It is hoped that this study will offer some new insights for the study of Chinese English learners' pragmatic failure and cultivation of their pragmatic competence in the field of foreign language teaching and learning.

\section{REFERENCES}

[1] Thoms J. 1983. "Cross-cultural pragmatic failure" In He Zhaoxiong Selected Readings for Pragmatics. Shanghai: Shanghai Foreign Language Education Press, 2003,pp 677-713.

[2] Li Yuansheng, Cross-Cultural Pragmatic Failures and Its Implication to College Classroom Teaching. Wuhan: North-Central Technology University, 2004.

[3] Austin, J.L. How to do things with words, NY:Oxford Universtiy Press, 1962.

[4] Xu Ping, A Study of Chinese students' Pragmatic Failure, Suzhou: Suzhou University, 2001.

[5] Peng Ying, Investigation and Analysis of Chinese University Students' Pragmatic Competence, Dalian: Dalian Maritime University, 2004.

[6] Li Yue'e, The Analysis of Pragmatic Failures in "Greetings" and Strategies, Foreign Language and Foreign Language Teaching, 1998, 11, pp28-32

[7] Li Chunfang, A Study on Chinese University Students' Pragmatic Failure of "Greetings", Guilin: Guangxi Normal University, 2002.

[8] Gu Tongqing, An Investigation of Non-English Major Postgraduates's Pragmatic Competence. Journal of Ningbo University, 2003, 1, pp86-89.

[9] Ellis, R. Understanding Second Language Acquisition. Oxford: Oxford University Press, 1985. 